\title{
SIG APLICADO NA DISCRIMINAÇÃO MORFOMÉTRICA DA MICROBACIA DO CÓRREGO DO VEADO - BROTAS/SP
}

\author{
Sérgio Campos ${ }^{1}$ \\ Sara Fernandes Martins ${ }^{2}$ \\ Marcelo Campos ${ }^{3}$
}

\begin{abstract}
RESUMO
As características físicas das microbacias são de suma importância, pois atuam no ciclo hidrológico, influenciando diretamente nos aspectos relacionados com a infiltração, a evapotranspiração e o escoamento superficial e subsuperficial. Esse trabalho teve como objetivo a aplicação de geoprocessamento na caracterização morfométrica da microbacia Córrego do Veado - Brotas (SP), através do Sistema de Informação Geográfica - Selva, buscando a preservação, racionalização de seu uso e recuperação ambiental. A base cartográfica utilizada foi a carta planialtimétrico de Brotas (SP) para extração das curvas de nível, da hidrografia e da topografia, em ambiente de Sistema de Informação Geográfica - Idrisi Selva, Para a determinação dos índices morfométricas. Os resultados mostram que os valores baixos da densidade de drenagem, associados à presença de rochas permeáveis, facilitar a infiltração de água no solo, reduzindo o escoamento superficial e o risco de erosão e da degradação do meio ambiente, bem como o valor baixo o factor de forma auxiliado pelo índice circular indica que a bacia tende a ser mais prolongada com menor susceptível à ocorrência de inundações mais acentuadas. O coeficiente de rugosidade ambiental parâmetro permitiu classificar o divisor de águas para a vocação com reflorestamento.
\end{abstract}

Palavras-chave: sensoriamento remoto, processamento de imagens, geologia.

\section{SIG APPLIED TO DISCRIMINATION MORPHOMETRIC THE STREAM VEADO WATERSHED - BROTAS / SP}

\begin{abstract}
\footnotetext{
${ }^{1}$ Prof. Titular, Departamento de Engenharia Rural, Faculdade de Ciências

Agronômicas/UNESP.seca@fca.unesp.br.

2 Prof. Dr., EDUVALE - Avaré. rcnardini@yahoo.com.

${ }^{3}$ Prof. Dr., Faculdade de Ciências Agronômicas/UNESP.seca@fca.unesp.br.
}

The physical characteristics of watersheds are very important because they act in the hydrological cycle, influencing directly on aspects of infiltration, evapotranspiration and surface and subsurface flow. This study aimed to the application of GIS in the morphometric characterization of the Stream Veado watershed - Brotas (SP) through the Geographic Information System - Selva, seeking the preservation, rationalization of their use and environmental recovery. The base map used was planialtimetric chart of Brotas (SP) for the extraction of contour lines, hydrography and topography in the geographic information system environment - Idrisi Selva, for determination of morphometric indices. The results show that the low values of the drainage density associated with the presence of permeable rock, to facilitate water infiltration, reducing runoff and the risk of erosion and environmental degradation, as well as the low value of the factor aided by the circular shape index indicates that the basin tends to be longer less susceptible to the occurrence of flooding more 
pronounced. The environmental roughness coefficient parameter allowed to classify the watershed for the vocation with reforestation.

Keywords: remote sensing, image processing, geology.

\section{INTRODUÇÃO}

O uso adequado dos recursos naturais exige estudos aprofundados para que sejam compreendidos os possíveis impactos provocados pela ação antrópica (QUEIRÓZ, 2008). A caracterização fisiográfica da microbacia do Córrego do Veado - Brotas (SP) é essencial para a elaboração e implementação de futuros projetos agroambientais regionais, pois os resultados auxiliarão na compreensão do escoamento superficial da microbacia.

A morfometria é uma ferramenta fundamental no diagnóstico de susceptibilidade à degradação ambiental, delimitação da zona ripária, planejamento e manejo de microbacias (MOREIRA e RODRIGUES, 2010), pois a sua caracterização permite descrever a formação geomorfológica da paisagem em sua variação topográfica (CHRISTOFOLETTI, 1969), bem como possui um papel significativo no condicionamento de respostas ligadas à erosão hídrica, gerado após eventos pluviométricos relevantes (ARRAES et al., 2010).

O monitoramento contínuo dos recursos hídricos é um instrumento essencial para melhor avaliar os fenômenos hidrológicos críticos, envolvendo tanto as secas quanto inundações. Com a adequada avaliação dos recursos hídricos utilizando o monitoramento dos dados relativos a uma microbacia, por exemplo, pode-se propor uma adequação da ocupação do solo em relação ao seu potencial e de suas limitações, tornando possível um manejo racional e equilibrado com a natureza, conquistando assim a sustentabilidade.

A implantação de uma política agrícola adequada e séria necessita de embasamento técnico e científico, com informações confiáveis e atualizadas sobre o grau de uso e utilização das terras e sobremaneira com o intuito de racionalizar e viabilizar o planejamento agrícola de determinada região, face à grande extensão territorial do país e à diversidade de uso, relevo, clima e tipos de solos encontrados nas diversas regiões.

O presente trabalho teve como objetivo a caracterização morfométrica da microbacia do Córrego do Veado - Brotas (SP) em ambiente do Sistema de 


\section{Periódica Eletrânica

Informações Geográficas Idrisi Selva, visando o planejamento e o manejo integrado dos recursos hídricos da área.

\section{MATERIAL E MÉTODOS}

A microbacia do Córrego do Veado localiza-se na porção norte do município de Brotas -SP, entre as coordenadas UTM 791200 a 798450 de longitude W Gr. e 7524450 a 7530400 de latitude S, com uma área de 2565ha.

O clima predominante do município, classificado segundo o sistema Koppen é do tipo Cwa - Clima subtropical úmido com invernos secos e verões quentes - em que a temperatura do mês mais frio é inferior à $18^{\circ} \mathrm{C}$ e do mês mais quente ultrapassa os $22^{\circ} \mathrm{C}$.

Na caracterização morfométrica da área foi utilizada a carta planialtimétrica do IBGE (1974), em escala 1:50.000, folha Brotas-SF-22-Z-B-III-4, com curvas de nível de 20 em 20 metros, para extração da rede de drenagem e da planialtimetria (Figura 1).

Após a delimitação da área da bacia obteve-se as características dimensionais da rede de drenagem, que são parâmetros quantitativos que permitem eliminar a subjetividade na sua caracterização. Na determinação desses parâmetros foi seguida a metodologia citada por OLIVEIRA e FERREIRA (2001) no cálculo do maior comprimento $(\mathrm{C})$, do comprimento do curso principal $(\mathrm{CP})$, do comprimento total da rede $(C R)$, do perímetro $(P)$ e da área $(A)$, as quais foram obtidas através do software Sistema de Informações Geográficas Idrisi Selva utilizado para manipulação, tratamento e análise dos dados gerados como as curvas de nível e a rede de drenagem da microbacia. 
Figura 1. Planialtimetria e hidrografia da microbacia do Córrego do Veado - Brotas (SP).

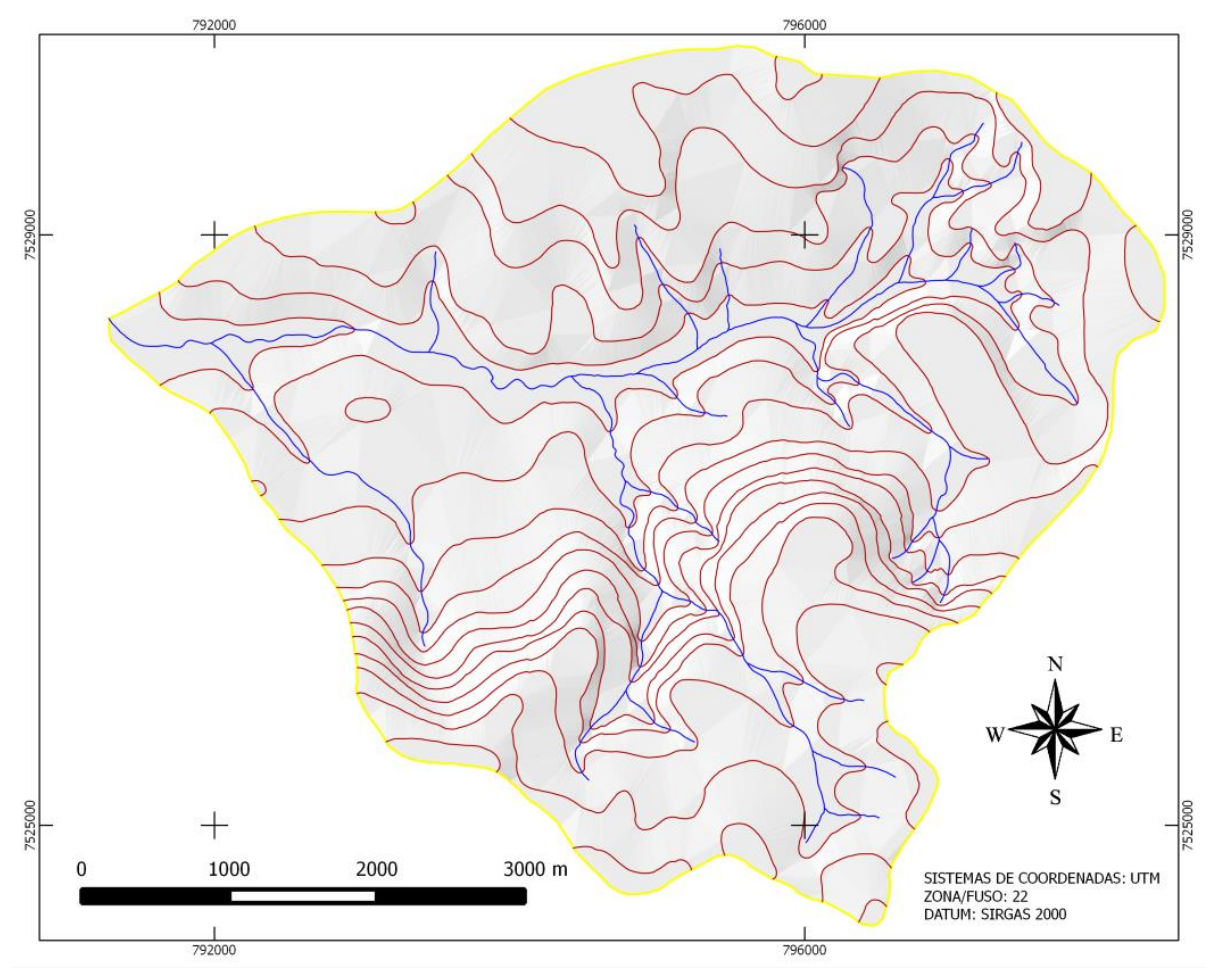

Na caracterização da composição e padrão de drenagem foram analisados os seguintes parâmetros: a densidade de drenagem (Dd), a extensão do percurso superficial (Eps), a extensão média do escoamento superficial (I), a textura da topografia $(\mathrm{Tt})$, o coeficiente de manutenção $(\mathrm{Cm})$, a rugosidade topográfica $(\mathrm{Rt})$ e 0 índice de forma $(\mathrm{K})$ foram determinados a partir da metodologia desenvolvida por CHRISTOFOLETTI (1969), bem como, o fator de forma (Kf), segundo ALMEIDA (2007).

A densidade hidrográfica é a relação existente entre o número de rios ou canais e a área da bacia hidrográfica (CHRISTOFOLETTI, 1969), sendo expressa pela equação: $\mathrm{Dh}=\mathbf{N} \cdot \mathbf{A}^{-1}$, onde: $\mathrm{Dh}$ - Densidade hidrográfica em $\mathrm{km}^{-2}, \mathbf{N}$ Número total de rios e $\mathrm{A}$ - Àrea da bacia hidrográfica em $\mathrm{km}^{2}$.

A declividade média foi obtida a partir da fórmula abaixo e classificada segundo LEPSCH et al., 2001: H = (D . L) 100/A, onde: H - Declividade média em \%, D - Distância entre as curvas de nível em m, L - Comprimento total das curvas de nível em m e A - Área da microbacia em $\mathrm{m}^{2}$. 


\section{Periádica Eletranica

O coeficiente de rugosidade $(\mathrm{CR}=\mathrm{Dd} . \mathrm{H}$, onde: $\mathrm{CR}=$ coeficiente de rugosidade; $\mathrm{Dd}=$ densidade de drenagem e $\mathrm{H}$ = declividade média), por ser um parâmetro que direciona o uso potencial das terras rurais, dependendo das características das atividades - agricultura, pecuária, silvicultura com reflorestamento ou preservação permanente -, foi usado para definir as classes de uso da terra das cinco microbacias hidrográficas da bacia do rio Soledade, que são: $\mathrm{A}$ (menor valor de $\mathrm{CR}$ ) - terras apropriadas à agricultura; $\mathrm{B}$ - terras apropriadas à pecuária; $C$ - terras apropriadas à pecuária e reflorestamento e $D$ (maior valor de CR) - terras apropriadas para florestas e reflorestamento (ROCHA e SILVA, 2001).

A densidade de drenagem é a correlação do comprimento total dos rios com a área da bacia, sendo obtida a partir da fórmula (SILVA et al., 2004): $\mathbf{D d}=1$. $\mathbf{A}^{-1}$, onde: $\mathrm{Dd}$ - Densidade de drenagem em $\mathrm{km} / \mathrm{km}^{2}, \mathrm{~L}$ - Comprimento total dos rios ou canais em $\mathrm{km}$ e A - Área da bacia em $\mathrm{km}^{2}$.

$O$ índice de circularidade, também denominado por alguns autores como índice de forma, representa a relação existente entre o perímetro e a área da bacia. O número calculado independe da área considerada, dependendo apenas da forma da bacia (SILVA et al., 2004). O menor valor possível a ser encontrado é 1,0, correspondendo a uma bacia circular (GANDOLFI, 1971). Esse parâmetro influencia a determinação da vazão e a intensidade de escoamento (SILVA et al., 2004). O índice de circularidade foi determinado pela equação: $\mathrm{TC}=12,57 P^{2}$, onde: $\mathrm{K}$ - Índice de circularidade; $\mathrm{P}$ - Perímetro da bacia em $\mathrm{km}$ e A Área da bacia em $\mathrm{km}^{2}$.

O coeficiente de compacidade é a relação entre o perímetro da microbacia e o perímetro de uma circunferência de um círculo de área igual da microbacia, que de acordo com VILLELA e MATTOS (1975) é um número adimensional que varia com a forma da microbacia, independentemente de seu tamanho. Se a bacia for irregular, maior será o coeficiente de compacidade e menos sujeita à enchentes, sendo: $\mathrm{Kc}=$ $1-1,25$ (redondas para ovaladas); 1,25 - 1,50 (ovaladas); 1,50-1,70 (blongas).

$\mathrm{Na}$ determinação do $\mathrm{Kc}$ utilizou-se da fórmula: $\mathrm{Kc}=0,28\left(P: A^{1 / 2}\right)$, onde: Kc - Coeficiente de compacidade, P - Perímetro em metros e A - Área de drenagem em $\mathrm{m}^{2}$.

A forma de uma microbacia pode ser comparada conforme algumas figuras geométricas conhecidas. Assim, o coeficiente de compacidade, o índice de 
circularidade compara a microbacia a um círculo e o fator de forma a compara a um retângulo. A forma da microbacia e a configuração do sistema de drenagem, estão associadas a estrutura geológica do terreno. O fator de forma (Ff) pode ser determinado pela seguinte equação: $\mathbf{F f}=\mathbf{A} / \mathbf{L}^{2}$, onde: $F f$ - Fator de forma, $A-A$ área de drenagem em $\mathrm{m}^{2}$ e $\mathrm{L}$ - O comprimento do eixo da bacia em $\mathrm{m}$.

A razão de relevo é a relação entre a diferença de altitude dos pontos extremos da bacia e seu comprimento (SCHUMM, 1956), que segundo CARVALHO (1981) demonstra que, quanto maiores os valores, mais acidentado será o relevo na região. Quanto maior a razão de relevo, maior será a declividade geral da bacia, portanto maior será a velocidade da água a escoar no sentido de seu maior comprimento. PIEDADE (1981) utilizou os seguintes valores para quantificar a razão de relevo: Razão de relevo baixa - 0,00 a 0,10; média - 0,11 a 0,30 e alta - 0,31 a 0,60.

\section{RESULTADOS E DISCUSSÃO}

A análise dos resultados obtidos para a microbacia do Córrego do Veado (Tabela 1) mostra que a área é de 25,65ha, o perímetro de $20 \mathrm{~km}$ e o fluxo de água se dá na direção E-W da microbacia, com um comprimento de $7 \mathrm{~km}$. O comprimento total da rede de drenagem é de $35 \mathrm{~km}$, demonstra que a microbacia apresenta-se com poucos canais de drenagem.

O formato é caracterizado fisicamente por parâmetros que relacionam com formas geométricas conhecidas, como o fator de forma que relaciona a um retângulo e o coeficiente de compacidade que relaciona a um círculo (RODRIGUES et al., 2011).

A forma é um parâmetro importante na determinação do tempo de concentração, pois determina o tempo necessário para que toda a mcirobacia contribua na saída da água após uma precipitação, uma vez que quanto maior o tempo de concentração menor será a vazão máxima de enchentes. O baixo valor do fator de forma $(0,52)$ obtido para o Córrego do Veado indica que a microbacia tem o formato mais ovalado. 
Tabela 1. Características morfométricas da microbacia Córrego do Veado, Brotas-SP.

\begin{tabular}{|c|c|c|}
\hline Características físicas & Unidades & Resultados \\
\hline \multicolumn{3}{|c|}{ Parâmetros dimensionais da microbacia } \\
\hline Área $(\mathrm{A})$ & $\mathrm{Km}^{2}$ & 25,65 \\
\hline Perímetro (P) & $\mathrm{Km}$ & 20 \\
\hline Comprimento do Rio Principal (C) & $\mathrm{Km}$ & 7 \\
\hline Comprimento da rede de drenagem total $(\mathrm{Cr})$ & $\mathrm{Km}$ & 35 \\
\hline Comprimento das curvas de nível (Cn) & $\mathrm{Km}$ & 122,1 \\
\hline Comprimento Vetorial & $\mathrm{Km}$ & 6,6 \\
\hline \multicolumn{3}{|c|}{ Características do relevo } \\
\hline Coeficiente de compacidade (Kc) & --- & 1,11 \\
\hline Fator forma (Ff) & --- & 0,52 \\
\hline Índice de circularidade (Ic) & --- & 0,87 \\
\hline Declividade média (D) & $\%$ & 9,52 \\
\hline Altitude média (Hm) & $\mathrm{M}$ & 705 \\
\hline Maior altitude (MA) & $\mathrm{M}$ & 842 \\
\hline Menor altitude $(\mathrm{mA})$ & $\mathrm{M}$ & 568 \\
\hline Amplitude altimétrica (H) & $\mathrm{M}$ & 274 \\
\hline Coeficiente de Rugosidade (CR) & --- & 12,28 \\
\hline \multicolumn{3}{|c|}{ Padrões de drenagem da microbacia } \\
\hline Ordem da microbacia $(\mathrm{W})$ & --- & $3^{a}$ \\
\hline Densidade de drenagem (Dd) & $\left(\mathrm{km} / \mathrm{km}^{2}\right)$ & 1,36 \\
\hline Coeficiente de Manutenção (Cm) & $\left(\mathrm{m} / \mathrm{m}^{2}\right)$ & 735,3 \\
\hline Extensão do Percurso Superficial (Eps) & $\mathrm{M}$ & 0,34 \\
\hline Gradiente de Canais (Gc) & $\%$ & 12,02 \\
\hline Índice de Sinuosidade (Is) & - & 1,06 \\
\hline Frequencia de Rios (Fr) & - & 0,77 \\
\hline
\end{tabular}

A área de uma microbacia é de extrema importância, pois ela influencia na quantidade de água produzida como deflúvio. A forma e o relevo atuam sobre a taxa e o regime desta na produção de água e na taxa de sedimentação.

O coeficiente de compacidade maior do que $1(1,11)$ e o fator de forma baixo $(0,52)$ permitiram afirmar que a microbacia, em condições normais de precipitação, excluindo-se eventos de intensidades anormais, é pouco susceptível a enchentes. Portanto, os resultados desses parâmetros mostram que a microbacia não possui formato circular, tendendo para a forma alongada, elíptica (SANTOS, 2001) e apresenta menor risco de enchentes sazonais, bem como o valor do índice de 


\section{Periódica Eletranica

circularidade de 0,87 permitiu confirmar também que a microbacia não possui forma próxima à circular, isto é, apresenta forma alongada.

Os baixos valores de Dd, Fr e Razão, provavelmente, estão associados à presença de rochas permeáveis (TONELLO et al., 2006), pois facilita a infiltração da água no solo diminuindo o escoamento superficial e o risco de erosão e degradação ambiental, pois quanto maiores esses valores mais intenso é o processo de erosividade do solo (RODRIGUES et al., 2008).

As características da rede de drenagem da microbacia mostram que a densidade de drenagem foi de $1,36 \mathrm{~km} / \mathrm{km}^{2}$. CHRISTOFOLETTI (1969) afirma que a densidade de drenagem da microbacia é baixa, pois o valor é menor que $7,5 \mathrm{~km} / \mathrm{km}^{2}$, enquanto que para VILLELA e MATTOS (1975), esse índice pode variar de $0,5 \mathrm{~km} / \mathrm{km}^{2}$, em microbacias com drenagem pobre, $3,5 \mathrm{~km} / \mathrm{km}^{2}$ ou mais, em microbacias excepcionalmente bem drenadas, indicando que a microbacia do Ribeirão Capuava apresenta baixa drenagem, indicando que esses valores baixos de densidade de drenagem estão geralmente associados a regiões de rochas permeáveis e de regime pluviométrico caracterizado por chuvas de baixa intensidade ou pouca concentração da precipitação.

A sinuosidade é um dos fatores controladores da velocidade de escoamento do canal, pois quanto mais próximo da unidade, demonstra que o rio segue exatamente a linha do talvegue, ou seja, apresenta-se com baixo grau de sinuosidade (SILVA et al., 2009).

O valor médio da extensão do percurso superficial $(0,34)$ e do coeficiente de manutenção $(735,3)$ confirma a presença de solos permeáveis na microbacia.

O conhecimento da declividade de um solo pode ser obtido de diversas maneiras, em campo e em laboratório, para estudos geológicos, hidrológicos, pedológicos, etc.

O grau de erosão dos solos é função da declividade média, que determina maior ou menor velocidade de escoamento da água pluvial sobre a superfície, associada à cobertura vegetal, ao tipo de solo e do tipo de uso da terra, obtida para cada bacia, segundo ROCHA (2001) e que segundo AVERBECK e SANTOS (1989), a variação na declive pode implicar em variações do tipo de solo.

A declividade média na microbacia do Córrego do Veado - Brotas (SP), da ordem de 9,52 permitiu classificá-la (CHIARINI e DONZELLI, 1973) como relevo 
como ondulado, sendo impróprio para o cultivo de culturas anuais e indicado para a o uso de pastagens em eventual rotação com culturas anuais, podendo ser também exploradas com culturas permanentes que protegem o solo (café, laranja, cana-deaçúcar, leguminosas como forma de adubação verde, etc.), pois são terras sujeitas à erosão e a prática da conservação do solo é imprescindível (LEPSCH et al., 2001). Portanto, atividades agrícolas em áreas impróprias e de forma inadequada deve ser considerada como uma prática de risco, pois se as práticas conservacionistas não forem utilizadas nestes casos, as bacias sofrerão grandes perdas de solos por erosão.

Para MOREIRA E RODRIGUES (2010), a declividade quanto mais alta apresenta relação direta com os processos erosivos devido à maior velocidade de escoamento superficial e menor infiltração das águas das chuvas, propiciando alteração na regulagem do sistema hidrológico e produção de água na mcirobacia.

O coeficiente de rugosidade por ser um parâmetro que direciona o uso potencial da terra com relação às suas aptidões para agricultura, pecuária ou reflorestamento (ROCHA, 2001), mostra também a realidade de uma microbacia, oferecendo uma contribuição simples, rápida e precisa ao planejamento, para melhor e mais justa exploração econômica, em função da vocação de suas terras (Pereira Filho, 1986), pois existe uma alta correlação entre o coeficiente de rugosidade e a capacidade de uso da terra, ao nível de $0,5 \%$ de erro.

O coeficiente de rugosidade é utilizado para diagnosticar as probabilidades de vir a ocorrer erosões. Desta forma, coeficiente de rugosidade de 12,28 permitiu classificar a microbacia do Córrego do Veado para vocação com uso por reflorestamento (Classe C), segundo ROCHA (2001), uma vez que os altos valores do coeficiente de rugosidade mostram que estas têm maiores chances de sofrer os efeitos da erosão, necessitando de medidas para prevenção e maior taxa de áreas cobertas pela vegetação.

\section{CONCLUSÕES}

A morfometria da microbacia do Córrego do Veado permitiu concluir que as variáveis morfométricas servirão para futuros planejamentos e gestões ambientais regionais. A microbacia apresenta altos riscos de susceptibilidade à erosão e 


\section{Periádica Eletranica

degradação ambiental, sendo fundamental a manutenção da cobertura vegetal e as zonas ripárias para conservação dos serviços ambientais. $O$ fator de forma e a densidade de drenagem, classificado como baixo, permitem inferir que o substrato tem permeabilidade alta com maior infiltração e menor escoamento da água. $\mathrm{O}$ Sistema de Informações Geográficas Idrisi Selva foi uma excelente ferramenta para a viabilização do monitoramento e gestão dos recursos hídricos da microbacia. $\mathrm{O}$ coeficiente de rugosidade permitiu classificá-la para vocação com uso por Pecuária/Reflorestamento (Classe D), pois altos valores mostram que estas têm maiores chances de sofrer os efeitos da erosão, necessitando de medidas para prevenção e proteção com cobertura vegetal.

\section{REFERÊNCIAS}

ALMEIDA, A.Q. de. Influência do desmatamento na disponibilidade hídrica da bacia hidrográfica do Córrego do Galo, Domingos Martins, ES. 2007. 80 p. Dissertação (Mestre em Engenharia Ambiental) - Universidade Federal do Espírito Santo, Vitória - ES.

ARRAES, c.I. ET AL. Morfometria dos compartimentos hidrológicos do Município de Jaboticabal, SP. Unopar., Londrina, v.9, n.1, p.27-32, 2010.

AVERBECK, H., SANTOS, R.D. Manual de fotointerpretação para solo. Rio de Janeiro, Minist. Agric., 1989. 33p.

CARVALHO, W.A. Relações entre relevos e solos da bacia do rio Capivara - município de Botucatu, SP. 1981. 193 p. Tese (Livre-Docência) - Universidade Estadual Paulista, Botucatu - SP..

CHIARINI, J.J., DONZELLI, P.L. Levantamento por fotointerpretação das classes de capacidade de uso das terras do Estado de São Paulo. Bol.Tec.Inst.Agron., Campinas, n.3, p.1-29, 1973.

CHRISTOFOLETTI, A. Análise morfometrica das bacias hidrográficas. Notícia Geomorfologia, Campinas, v.9, n.18, p.35-64, 1969.

GANDOLFI, P.A. Investigações sedimentológicas, morfométricas e físio-químicas nas bacias do Moji-Guaçu, do Ribeira e do Peixe. Tese (Livre Docência). Departamento de Geologia e Mecânica dos Solos, EESC-USP, São Carlos, SP. 


\section{Periádica Eletrânica

INSTITUTO BRASILEIRO DE GEOGRAFIA E ESTATÍSTICA - IBGE. Cartas do Brasil. Superintendência de Cartografia do Ministério do Planejamento e Coordenação Geral do Brasil. Folha de Brotas, 1974.

LEPSCH, J.F. et al. Manual para levantamento utilitário do meio físico e classificação de terras no sistema de capacidade de uso. Campinas, Soc.Bras.Cien.do Solo, 2001.175p.

MOREIRA, L., RODRIGUES, V.A. Análise morfométrica da microbacia da Fazenda Edgárdia Botucatu (SP). Eletr.Eng.Florestal. Garça, v.16, n.1, p.9-21, 2010.

MOTA, S. Planejamento urbano e preservação ambiental. Fortaleza, Edições UFC, 1981.242p.

OLIVEIRA, A., FERREIRA, E. Caracterização de sub-bacias hidrográficas. Lavras: UFLA/FAEPE, 64p. Geografia Física v.3, n.1, p.112-122, 2001.

PEREIRA FILHO, W. Capacidade de uso da terra em função do coeficiente de rugosidade. 1986. 48 p. Monografia - Universidade Federal de Santa Maria, Santa Maria - RS.

PIEDADE, G.C.R. Evolução de voçorocas em bacias hidrográficas do município de Botucatu, SP. Botucatu, 1980. 161 p. (Tese de Livre Docência) - FCA/UNESP, 1981.

QUEIRÓZ, H.A. Caracterização fisiográfica e de alguns atributos físicos e químicos dos solos da microbacia Jardim Novo Horizonte, em Ilha Solteira, SP. 2007. 61 p. Dissertação (Mestrado em Agronomia). Universidade Estadual Paulista, Ilha Solteira - SP. 61p.

ROCHA, J. S. M., SILVA, S.M.J.M. Manejo Integrado de Bacias Hidrográficas. Santa Maria: UFSM, 2001. 302p.

SCHUMM, S.A. Evolution of drainage systems and sloes in bedlands at Perth Amboy. New Jersey. Bull. Geol. Soc. Am., Colorado, v.67, p.597-646, 1956.

SILVA, M. C. et al. Morfometria da microbacia do córrego fundo no Município de Aquidauna, MS. In: SIMPÓSIO DE GEOTECNOLOGIAS NO PANTANAL, 2, 2009, Corumbá. Anais... São José dos Campos: Instituto Nacional de Pesquisas Espaciais -

INPE, 2009. p.290-295.

SILVA, A. M.; SCHULZ, H. E.; BARBOSA, C. P. Erosão e Hidrossedimentologia em Bacias hidrográficas. São Carlos : RiMa. 141p. 2004. 
SANTOS, A.R. dos. Caracterização morfológica, hidrológica e ambiental da bacia hidrográfica do rio Turvo Sujo, micro-região de Viçosa, MG. 2001, 141 p. Tese (Doutorado Engenharia Agrícola) - Universidade Federal de Viçosa, MG.

RODRIGUES, FM, PISSARRA, TCT, CAMPOS, S. Caracterização morfométrica da microbacia hidrográfica Córrego da Fazenda Glória, Município de Taquaritinga. Irriga: Botucatyu, v.13, n.1, p.310-322. 2008.

TONELLO, K.C. DIAS, H. C. T., SOUZA, A. L. de., RIBEIRO, C.A. A.S. R. \& LEITE, F.P. Análise hidroambiental da bacia hidrográfica da cachoeira das Pombas, Guanhães, MG. Árvore, Viçosa-MG, v.30, n.5, p.849-857, 2006.

VILLELA, S.M., MATTOS, A. A Hidrologia aplicada. São Paulo: McGraw-Hill do Brasil, p. 245, 1975. 